\title{
LAS LIMITACIONES JURÍDICAS DE LA COOPERATIVA EN EL SOCIALISMO. PERSPECTIVAS PARA EL PERFECCIONAMIENTO DE SU REGULACIÓN EN CUBA
}

\author{
POR \\ Orestes RODRÍGUEZ MUSA ${ }^{1}$ y \\ Orisel HERNÁNDEZ AGUILAR ${ }^{2}$
}

\section{RESUMEN}

En el presente trabajo se ofrece una valoración de las transformaciones legales que, en materia de cooperativas, acompañan el recién iniciado proceso de actualización del modelo socioeconómico socialista cubano, así como las perspectivas que dicho proceso abre aesta forma empresarial en la construcción del socialismo próspero y sostenible que el país necesita.

Para ello, se parte de una caracterización general de la regulación jurídica de la cooperativa en los modelos socialistas, con especial énfasis en la concepción de su naturaleza y en sus relaciones con el Estado, a fin de comprender las restricciones impuestas por el Derecho al asignarle su rol en el sistema socioeconómico.

Partiendo de esta base, se analizaránlas limitaciones que ha presentado la regulación de la cooperativa en Cuba en la etapa socialista, relativas a su naturaleza, reconocimiento del derecho para asociarse en cooperativas, sector de la economía en que se desarrolla, fines a los que se concibe, dinámica de funcionamiento, etc. y que requieren ser superadas en el actual

\footnotetext{
${ }^{1}$ Profesor del Departamento de Derecho de la Facultad de Ciencias Sociales y Humanísticas de la Universidad de Pinar del Río, Cuba. Investigador del Centro de Estudios de Desarrollo Cooperativo y Comunitario (CEDECOM) adscrito a la Universidad de Pinar del Río, Cuba e investigador de la Asociación Internacional de Derecho Cooperativo (AIDC) con sede en la Universidad de Deusto, España. Dirección de correo electrónico: musa@upr.edu.cu

${ }^{2}$ Profesora del Departamento de Derecho de la Facultad de Ciencias Sociales y Humanísticas de la Universidad de Pinar del Río, Cuba. Investigadora de la Asociación Internacional de Derecho Cooperativo (AIDC) con sede en la Universidad de Deusto, España. Dirección de correo electrónico: oriselha@upr.edu.cu
}

REVESCO No 117 - MONOGRÁFICO: Las sociedades cooperativas construyen un mundo mejor - ISSN: 1885-8031 - www.ucm.es/info/revesco

http://dx.doi.org/10.5209/rev_REVE.2015.v117.48147

Fecha de recepción: 12/10/2014

Fecha de aceptación: 21/01/2015 
proceso de cambios que vive el país para que la institución pueda desplegar sus diversas potencialidades.

Por último, se realizara una aproximación crítica a las más recientes transformaciones jurídicas que ha sufrido la cooperativa en el marco del proceso de perfeccionamiento del sistema socioeconómico socialista cubano, así como a las perspectivas que abre dicho proceso para que el Derecho pueda jugar su papel regulador y potenciador en torno a ella.

Palabras clave: cooperativismo; modelos socialistas; relaciones cooperativas-Estado

Claves Econlit: P130

\title{
COOPERATIVE LEGAL LIMITATIONS ON SOCIALISM. PROSPECTS FOR THE IMPROVEMENT OF THEIR REGULATION IN CUBA
}

\begin{abstract}
This paper examines the legal transformations that accompany the newly initiated updating process of the Cuban socialist socioeconomic model and the perspectives that this process opens to this form of business in building the prosperous and sustainable socialism the country needs. The starting point is therefore a general description of the legal regulation of cooperatives in socialist models, with special emphasis on the conception of their nature and their relationship with the State, in order to understand the constraints imposed by law in assigning their role in the socioeconomic system. On this basis, an analysis is made of the limitations presented by cooperative regulation in Cuba under socialism, relating to their nature, the recognition of their right to associate in cooperatives, sector of the economy in which they operate, purpose with which they are created, form of operation, etc. These limitations must be overcome in the ongoing process of change that the country is undergoing so that the institution can develop its different potentialities. Finally, this paper makes a critical approach to the most recent legal transformations faced by cooperatives within the upgrading process of the Cuban socialist socioeconomic system and to the perspectives this process offers so that law can play its regulatory and enhancing role in this regard.
\end{abstract}

Keywords: cooperativism, socialist models, cooperative-state relationship.

REVESCO No 117 - MONOGRÁFICO: Las sociedades cooperativas construyen un mundo mejor - ISSN: 1885-8031 - www.ucm.es/info/revesco 


\section{INTRODUCCIÓN}

El Derecho, en tanto elemento regulador de la sociedad, desempeña diversas funciones. Sistematizaciones teóricas aparte, debe reconocerse que una de las principales responsabilidades de cualquier ordenamiento jurídico es la de desempeñar el rol de agente de transformación social, sea legitimando a posteriori o promoviendo directamente el cambio (Laso, 1977). Siendo así, la dimensión jurídica en la construcción de un mundo mejor es imprescindible.

Si se entiende que ese proyecto de sociedad mejor a construir debe distinguirse por ser una "civilización de la solidaridad", se impone "pensar no sólo en una estructura económica y política radicalmente distinta sino, sobre todo, en una nueva sociedad que valorice los conceptos de bien común, de interés público, de derechos universales, de gratuidad" (Lowry, 2003:35). Dentro de tal aspiración se inscribe, por méritos propios, la cooperativa.

Al ser muchas veces incomprendida la esencia y naturaleza compleja de esta figura, cierto es que no ha podido desempeñar todo su potencial como ente dinamizador de relaciones sociales inclusivas, democráticas y socializadoras de bienes, saberes y valores. En ese sentido, su regulación legal adeuda, no poco, al enriquecimiento social de nuestro entorno.

Ante la trascendencia de la regulación de la cooperativa en la construcción de ese mundo mejor al que aspiramos, el presente trabajo se propone examinar cómo se ha venido avanzando en el contexto cubano en este sentido, donde aún queda mucho por hacer. Por tal motivo el objetivo planteado es valorar las recientes transformaciones legales que acompañan el proceso de actualización del modelo socioeconómico cubano en materia de cooperativas, así como las perspectivas que dicho proceso abre a sus potencialidades de fomentar favorables cambios sociales.

Para ello se partirá de un análisis de las premisas que históricamente han caracterizado la regulación jurídica de la cooperativa en los modelos socialistas, a fin de comprender cómo se ha comportado la relación Derecho-cooperativa al intentar estimularse esta última. En un segundo momento se expondrán las limitaciones que ha presentado la regulación de la cooperativa en Cuba en la etapa socialista. Por último, se realizara una aproximación crítica a los más recientes cambios jurídicos que ha sufrido la cooperativa en el marco del proceso de perfeccionamiento del sistema socioeconómico socialista cubano, así como a las perspectivas 
que dicho proceso abre al Derecho para que pueda jugar en torno a ella su papel transformador.

\section{LA COOPERATIVA EN LOS ORDENAMIENTOS JURÍDICOS SOCIALISTAS: UNA APROXIMACIÓN CRÍTICA EN RETROSPECTIVA}

La cooperativa en los ordenamientos jurídicos socialistas ha estado muchas veces marcada por su relación con el Estado, puesto que éste, al regularlas y relacionarse jurídicamente con ellas, bien ha mutilado su naturaleza o les ha obstaculizado el despliegue de sus virtudes socioeconómicas.

Sin irrespetar la premisa de que son diversos los contextos en los que se ha intentado construir el socialismo, es posible determinar en ellos rasgos comunesen la manifestación jurídica de la cooperativa:

En cuanto a la naturaleza de la cooperativa, la doctrina y el ordenamiento jurídico prevalecientes en el socialismo real confundieron categorías de la Economía y el Derecho, para dar paso a la concepción que la define como una forma de propiedad (Álvarez, 1989; Azcuy, 2000; Jálfina, 1981; Vega, 1988), y que a consideración de los autores resultó reduccionista, pues ponderó el carácter colectivo del uso, disfrute y disposición del patrimonio cooperativo, en detrimento de sus intrínsecos principios de funcionamiento a lo interno y a lo externo, en tanto espacio asociativo-empresarial de esencia compleja. De esta forma se desvirtuó a la figura, sin que se obtuviera de ella los resultados esperados.

En otro orden, la instrumentación jurídica de la cooperativa y su formalización no fueron como regla resultado de iniciativas consientes de obreros y campesinos que la hayan procurado para solucionar sus necesidades socioeconómicas comunes, sino promovida -y hasta forzada- por resortes ideológicos-políticos que veían en ella una opción para la socialización de la propiedad y la abolición de la explotación del trabajo ajeno.

Sin ánimo de cuestionarnos el fin de aquel proceso, lo cierto es que la revolución cultural a la que llamó LENIN, como requisito imprescindible para hacer efectiva la cooperación y que debía conducir inequívocamente hacia el socialismo, no resultó -tras su muerte- lo que se esperaba, sino que -por lo general- devino en fracaso económico y social (Ferrero, 2006; Sánchez).

REVESCO No 117 - MONOGRÁFICO: Las sociedades cooperativas construyen un mundo mejor - ISSN: 1885-8031 - www.ucm.es/info/revesco 
Por tal motivo, hoy sería pertinente afirmar que las cooperativas deben surgir en el socialismo del ejercicio legítimo del derecho de asociación, como vía efectiva para la autoorganización de las personas en función de la satisfacción de sus necesidades comunes y las de la comunidad; no de un acto administrativo que condicione la gestión del patrimonio y/o de la fuerza de trabajo.

Por otra parte, debe recordarse que con las revoluciones socialistas, el poder político que conquista la clase obrera no está respaldado -originariamente- por los medios materiales necesarios para su reproducción. Por consiguiente, la conquista del poder político se ha visto obligada a surgir a la par de la formal apropiación de los medios generadores de la riqueza material y espiritual de esa clase.

La fórmula empleada por el socialismo real, para conseguir esta apropiación colectiva, fue la nacionalización de los medios de producción y la consiguiente constitucionalización de un sistema económico basado en la propiedad social (V.gr.: art. 4 de la Constitución de la URSS de 1936; art. 16 de la Constitución yugoslava de 1946; art. 8 de la Constitución búlgara de 1947; art. 7 de la Constitución rumana de 1948; art. 4.1. de la Constitución húngara de 1949; art. 6 de la Constitución china de 1954; art. 12 de la Constitución norvietnamita de 1960). Esta última se ha manifestado a través de la propiedad estatal, entendida como propiedad de todo el pueblo y, por consiguiente, máxima expresión de socialización y en la propiedad cooperativa, considerada menos avanzada que la propiedad de todo el pueblo y, por tanto, con el propósito de irse acercando a ella (V.gr.: art. 5 y art. 10 de las constituciones de la URSS de 1936 y 1977 respectivamente). Lo anterior explica el papel subsidiario con que se ha instrumentado la cooperativa con respecto al Estado en los ordenamientos jurídicos socialistas (Ioffe, 1960; Jálfina, 1981; Petr, 2004; Rodríguez).

Sin embargo, en la práctica ha demostrado la propiedad estatal no ser siempre la forma ideal para empoderar de los medios de producción a la clase trabajadora, que en muchos casos termina desentendiéndose en favor de la burocracia, la corrupción y la ineficiencia. El Estado socialista debe permanecer como garante del poder político de los trabajadores, del consenso, de los recursos naturales y de las conquistas sociales que merezcan su intervención; pero nunca convertirse en la fórmula omnipresente para la gestión.

A consecuencia de lo anterior, ha adolecido también la cooperativa de altos niveles de dependencia para con el Estado. Esto se ha expresado -entre otros aspectos- en el hecho de 
que el Estado elabora, aprueba e impone un plan de producción que vincula jurídicamente a las cooperativas, para garantizar el cual la empresa estatal constituye la única o principal proveedora del aseguramiento material y técnico que la cooperativa requiere para el desarrollo de su objeto social, además de ser aquella la única o principal beneficiaria de la actividad económica de estas (Ioffe; Jálfina, 1981; Rodríguez).

La planificación de la economía ha resultado -y resulta- consustancial al socialismo, en tanto constituye la vía para combatir las insuficiencias del mercado en la asignación racional de los recursos a la sociedad. Pero, el modelo socialista clásico trató de resolver el problema de la equidad en esta distribución mediante un mecanismo económico en el cual el papel de la planificación centralizada era casi absoluto (Carranza, Gutiérrez \& Moreal, 2004), lo que trajo consigo restricciones a algunos de los caracteres identitarios de la cooperativa, en especial a su autonomía (Kaplan de Drimer \& Drimer, 1989).

Sin embargo, “...aún en los países de planificación centralizada, las cooperativas pueden desempeñar un importante papel, sobre todo al favorecer la descentralización en la ejecución de esos planes, facilitando una mayor autonomía a nivel de las empresas, aliviando la organización burocrática y estimulando la eficiencia y productividad a través de su competencia con las empresas estatales" (Kaplan de Drimer \& Drimer, 1989:503), a lo que podemos agregar su necesaria participación en la elaboración, aprobación y control del plan.

A consideración de los autores, la forma en que el Derecho socialista ha acogido las relaciones entre el Estado y las cooperativas, es resultado de una interpretación del pensamiento marxista poco consecuente con su método dialéctico, en tanto reflejan la pretensión fallida de transitar de una formación económico-social a otra por decisión políticojurídica y no mediante el gradual desarrollo de las fuerzas productivas (Yera, 2007). Por tanto la cooperativa ha de concebirse jurídicamente en el socialismo en armonía con sus rasgos y principios típicos; solo así podrá desplegar de manera efectiva su potencial productivo y socializador.

REVESCO No 117 - MONOGRÁFICO: Las sociedades cooperativas construyen un mundo mejor - ISSN: 1885-8031 - www.ucm.es/info/revesco 


\section{LAS LIMITACIONES JURÍDICAS DE LA COOPERATIVA EN CUBA DURANTE LA ETAPA SOCIALISTA Y ANTES DEL ACTUAL PROCESO DE PERFECCIONAMIENTO DEL MODELO SOCIOECONÓMICO NACIONAL}

Si bien los antecedentes jurídicos de la cooperativa en Cuba han de encontrarse en etapas precedentes (Fernández, 2012; Rodríguez, 2011), en atención al objetivo de este trabajo se circunscribirá su estudio en esta ocasión a su etapa socialista, donde siempre ha resultado innegable la influencia del modelo soviético, esto como resultado de la radicalización de la revolución popular cubana de 1959 en su enfrentamiento a lo más reaccionario de la burguesía nacional y al gobierno norteamericano. No obstante, es necesario reconocer que algunas variaciones en esta normativa fueron introducidas a partir del año 1992 tras la caída del campo socialista y la subsiguiente flexibilización del sistema económico nacional.

Este marco jurídico, hastainiciado el proceso de actualización del modelo socioeconómico - en el que indagaremos más adelante - estaba compuesto: con carácter general, por el artículo 20 de la Constitución de 1976; con carácter supletorio,porlos artículos del 145 al 149 del Código Civil, Ley 59 de 16 de julio de 1987 y, con carácter especial,porla Ley de Cooperativas de Producción Agropecuaria y de Créditos y Servicios, Ley 95 del 2 de noviembre de 2002 y por el Decreto Ley 142 de 20 de septiembre de 1993, Sobre las Unidades Básicas de Producción Cooperativa.

Sobre esta base, pasemos a continuación a valorar algunas de las limitaciones más significativas que tal legislación -aún vigente en su totalidad- impone al desarrollo cooperativo del país.

\section{a) Naturaleza jurídica}

En el ordenamiento jurídico cubano se entiende a la cooperativa como una forma de propiedad a partir del 24 de febrero de 1976 con la proclamación del texto constitucional socialista. El artículo 20 de este cuerpo jurídico (reformado en 1992), resalta desde un inicio que "Esta propiedad cooperativa es reconocida por el Estado...". Por su parte, el Código Civil, al ubicar a la cooperativa en su TÍTULO II: DERECHO DE PROPIEDAD, CAPÍTULO II: FORMAS DE PROPIEDAD, bajo la denominación de la SECCIÓN

REVESCO No 117 - MONOGRÁFICO: Las sociedades cooperativas construyen un mundo mejor - ISSN: 1885-8031 - www.ucm.es/info/revesco 
TERCERA: Propiedad cooperativa; deja en claro la concepción que asume para explicar la esencia de la figura.

Esta concepción, igualmente presente en la legislación especial agraria, lleva a advertir que “... el modelo jurídico adoptado, está distanciado de la naturaleza social de la institución cooperativa, pues en él se privilegia el componente administrativo-patrimonial, sobre el asociativo..." (Fernández, 2006:27).

La cooperativa, para conseguir la socialización de la propiedad a que está llamada en Cuba, debe configurarse por el Derecho como un espacio asociativo, que propicie el desarrollo efectivo de un proceso de producción - apropiación de bienes y servicios en el que prime la equidad, la voluntariedad y la autonomía en su constitución y funcionamiento, al interior de un clima institucional que guíe su contribución a la solución de los problemas económicos y culturales de la comunidad en que se desarrolla.

\section{b) Reconocimiento del derecho de asociarse en cooperativas}

El artículo 20 del magno texto cubano precisa que las cooperativas que se desenvuelven en el sector agropecuario (las únicas existentes hasta hace muy poco en el país) son resultado del ejercicio del "derecho a asociarse" de "los agricultores pequeños". Por tanto, la expresa alusión en el precepto de sus sujetos destinatarios se ha interpretado como un límite constitucional al derecho de asociarse en cooperativas para otros trabajadores, lo que merecería una explicación histórica:

Cuba, desde la proclamación de su carácter socialista, ha buscado mecanismos de socialización de la propiedad, como vía para excluir “...la división de los hombres en poseedores de los medios de producción y desposeídos de ellos, y que las relaciones personales se basen en la colaboración y ayuda mutua" (Álvarez, 1989:84). Este propósito genuinamente revolucionario desembocó en que para marzo de 1968 prácticamente todos los medios útiles para la producción habían sido intervenidos y pasaron a propiedad estatal, entendiéndoseasí terminado el proceso de socialización de la propiedad privada (Casullera, 1986).

Sobre esta base, la Constitución socialista cubana de 1976 estableció en su artículo 14 que: "En la República de Cuba rige el sistema socialista de economía basado en la propiedad socialista de todo el pueblo sobre los medios de producción y en la supresión de la REVESCO No 117 - MONOGRÁFICO: Las sociedades cooperativas construyen un mundo mejor - ISSN: 1885-8031 - www.ucm.es/info/revesco 
explotación del hombre por el hombre". El complemento y principal modo de expresión de este principio constitucional, que rectorea desde entonces el modelo económico cubano, ha de hallarse en el precepto que consigna: "La propiedad estatal socialista, que es la propiedad de todo el pueblo...", para, taxativamente y en reglón seguido, definir el objeto de esta forma de propiedad con una amplísima gama de objetivos económicos de la que escapan, por excepción expresa, "...las tierras que no pertenecen a los agricultores pequeños o a cooperativas integradas por los mismos...”.

Así, el respaldo legal e institucional necesario para que los trabajadores cubanos pudieran asociarse en cooperativas quedó constreñidoal sectoragropecuario de la economía, panorama que no cambio con las reformas al sistema económico cubano introducidas en 1992.

c) Sector de la economía en que se desarrolla

Como hemos dicho, el marco legal socialista de las cooperativasen Cuba solo contemplaba (hasta hace par de años) la creación de cooperativas en el sector agropecuario de la economía, lo que ha generado su estudio y desarrollo jurídico únicamente desde el Derecho Agrario.

Para explicarlo se ha razonado que “...hubiera sido un retroceso desde el punto de vista social convertir a los obreros en propietarios cooperativos. La organización cooperativa quedó entonces como un escalón de avance para los campesinos que continuaban la explotación individual de la tierra" (Azcuy, 2000:53).

Del análisis de esta idea queda claro que la figura fue percibida como intermedia y transitoria entre la propiedad estatal y la privada o individual, para la transformación de la última en la primera. Este criterio, de alto contenido político-ideológico, siempre limitó el desarrollo práctico y jurídico de la cooperativa en otros sectores de la economía.

\section{d) Fines a cuyos efectos se concibe legalmente}

Para comprender la magnitud y adaptabilidad de los fines de las cooperativa puede partirse de un presupuesto esencial, aunque no único, que de alguna forma condiciona su desarrollo: “...lo que mueve a las cooperativas es la satisfacción de las necesidades de desarrollo humano de sus miembros; las cuales están inevitablemente ligadas a las 
necesidades de sus comunidades aledañas y de la nación, e incluso de la «gran familia humana»" (Piñeiro, 2011:10). Nada ajeno a esta quintaesencia es admisible y todo aquello que a ella responda debe ser aceptado y promovido por el Derecho. Sin embargo, los fines para los que se concibe la cooperativa -agropecuaria- están expresados en sentido restrictivo por la Constitución de la República: “...producción agropecuaria...” y “...obtención de créditos y servicios estatales...".

No obstante estos fines previstos constitucionalmente, estudiosos del cooperativismo cubano (Jiménez, 2005) sostienen que la creación de las cooperativas se inserta en las megafinalidades propias del desarrollo rural emprendido con el triunfo de la Revolución y que consideró los siguientes aspectos: el fomento de asentamientos poblacionales para garantizar el bienestar de las comunidades; el desarrollo de una determinada infraestructura para el desarrollo del campo (comunidades, viales, transporte, electricidad, etc.); el desarrollo de programas de educación, salud, y otros servicios a la población; la creación de mejores condiciones laborales y de vida que propiciaron la elevación de las aspiraciones y motivaciones personales de los trabajadores del campo.

Pero estas perspectivas programáticas no alcanzaron reflejo normativo que pusiera en evidencia la responsabilidad y el papel social de las cooperativas más allá del ámbito administrativo-productivo. Esto se hace evidente con la lectura de los artículos 8 y 9 de la Ley de Cooperativas de Producción Agropecuaria y de Créditos y Servicios, que al consignar los fines fundamentales de las cooperativas agropecuarias cubanas lo hace en extremo apegada al carácter reduccionista -por economicista- que ya hemos criticado y que le impiden al Derecho jugar su papel transformador.

\section{e) Dinámica de funcionamiento}

El funcionamiento de las cooperativas puede entenderse en dos planos bien definidos y separados aunque vinculados entre sí: el interno que explica la lógica de constitución, el régimen de los socios, los órganos sociales, régimen económico, la solución de conflictos; y el externo que abarca lo tocante a su relación como persona jurídica con otras personas naturales o jurídicas distintas de sus socios.

En la Constitución socialista cubana no se sientan principios generales para el control de la cooperativa por sus asociados, pues si bien se establece que ellas “...administran, 
poseen, usan, y disponen de los bienes de su propiedad..." (art. 20), la participación de los miembros en la empresa económica común que la cooperativa supone, siempre será más dinámica y compleja que el mero ejercicio de facultades sobre bienes. Surgirán problemáticas de necesaria decisión colectiva, relaciones jerárquicas, de representación y otras interioridades que el ordenamiento jurídico debe encauzar hacia un destino apropiado.

La legislación especial que desarrolla el tema cooperativo también manifiesta limitaciones para el funcionamiento de las cooperativas agropecuarias (Fernández, 2012):

- En cuanto a su constitución como personas jurídicas, su supeditación a un sistema de creación por autorización administrativa.

- La carencia de un régimen jurídico común para aspectos tan importantes como la determinación de la condición de socio, concepción de los órganos sociales y su periodo de mandato, el régimen de control democrático de los cooperativistas respecto a la gestión de estos, etc.

- Insuficiente nivel de protagonismo de las cooperativas y los socios en el enfrentamiento de las contingencias existenciales de las mismas, debido a un paternalismo excesivo de la Administración Pública.

- Ineficiente empleo del contrato en las relaciones empresariales de las cooperativas, como vía adecuada para la exigencia y cumplimiento de responsabilidades jurídicas.

- Las reservas aun no muy explotadas de la cooperativa en sus relaciones con las organizaciones políticas, sociales y de masas; relaciones estas que deben diversificarse desde la comprensión del rol social y activo de las cooperativas en el entorno comunitario, como sujetos del desarrollo local.

Las limitaciones jurídicas apuntadas, entre otras, han impedido al movimiento cooperativo nacional su expansión y desarrollo, privándose así alasociedad de las múltiples contribuciones que la empresa cooperativa podría ofrecer para la construcción del socialismo próspero y sostenible que el país necesita.

REVESCO No 117 - MONOGRÁFICO: Las sociedades cooperativas construyen un mundo mejor - ISSN: 1885-8031 - www.ucm.es/info/revesco 


\section{LA REgULACIÓN JURÍdiCA DE LA COOPERATIVA EN CUBA A PARTIR DEL PROCESO DE ACTUALIZACIÓN DEL MODELO SOCIOECONÓMICO SOCIALISTA. REALIDAD Y PERSPECTIVAS}

La situación antes descrita comienza a experimentar cambios a partir de abril de 2011 cuando el VI Congreso del Partido Comunista de Cuba aprobó los Lineamientos de la Política Económica y Social del Partido y la Revolución (en lo adelante Lineamientos) (VI Congreso del Partido Comunista de Cuba, 2011), con el objetivo de sentar las pautas necesarias para conducir el proceso de actualización del modelo económico socialista en el país.

Los puntos del 25 al 29 de los Lineamientos, agrupados bajo el título de "LAS COOPERATIVAS", establecen pautas medulares para la inserción de estas en un nuevo "MODELO DE GESTIÓN ECONÓMICA", las cuales han sido desarrolladas por la legislación -experimental- promulgada a partir de diciembre de 2012.

Dentro de este nuevo panorama conviene examinar algunas aristas que han evidenciado cambios significativos y otras que, a pesar de las modificaciones, aún pueden ser optimizadas.

- La técnica de la regulación legal de la cooperativa.

En primer orden tenemos que la Constitución de la República de Cuba de 24 de febrero de 1976 continúa constriñendo el reconocimiento de la cooperativa a la esfera agropecuaria, toda vez que solo los agricultores pequeños poseen el derecho a asociarse en cooperativas según la Constitución.

Pese a ello se ha promulgado el Decreto - Ley 305 de 11 de diciembre de 2012, "De las Cooperativas no Agropecuarias" (en lo adelante DL305/12). En este sentido resulta curioso que sí se refiera en los POR CUANTOS de este Decreto-Ley al Código Civil, cuando este último adolece de las mismas limitaciones que la Constitución en la regulación de la cooperativa. La explicación a esto puede venir asociada al carácter experimental que se le reconoce a dicha norma y sus disposiciones complementarias. No obstante, de mantenerse la política de diversificación y perfeccionamiento del sector cooperativo, resultará pertinente dotar de coherencia al ordenamiento jurídico, incluyendo una modificación constitucional que respalde a estas nuevas cooperativas.

REVESCO No 117 - MONOGRÁFICO: Las sociedades cooperativas construyen un mundo mejor - ISSN: 1885-8031 - www.ucm.es/info/revesco 
Con la introducción de estas últimas normas se complejiza aún más el sustento legal de la cooperativa en Cuba, dada la presencia de disposiciones, de diverso rango, emanadas de diferentes órganos u organismos estatales, destinadas a reglamentarlas en sus múltiples formas. En este sentido destacan, entre otras, para regir las Cooperativas de Producción Agropecuaria (CPA) y las de Créditos y Servicios (CCS), sendos Reglamentos Generales aprobados por Acuerdo del Comité Ejecutivo del Consejo de Ministros el 17 de mayo de 2005 (en lo adelante RG/05 de la CPA y RG/05 de la CCS); para las Unidades Básicas de Producción Cooperativa (UBPC) la Resolución 574 de 13 de agosto de 2012 del Ministerio de la Agricultura, "Reglamento General de las Unidades Básicas de Producción Cooperativa" (en lo adelante RG/12 de las UBPC); y por último, destinado a las Cooperativas no Agropecuarias, el Decreto 309 de 28 de noviembre de 2012, "Reglamento para las Cooperativas no Agropecuarias de Primer Grado" (en lo adelante D309/12).

La anterior aproximación a la vigente plataforma legal de la cooperativa en Cuba evidencia que esta se integra por un conjunto de normas jurídicas que presentan poca sistematicidad y coherencia entre sí, parcelando los caracteres jurídicos de la figura en atención al sector de la economía en que se desarrollan, lo que a su vez conlleva a la existencia de antinomias y contradicciones derivadas de la diversidad de sus bases contextuales, así como del reglamentarismo excesivo. Sigue siendo, en consecuencia, el plano técnico legal de la regulación de las cooperativas un aspecto que requiere de atención, a fin de superar las carencias e insuficiencias que en él subsisten.

\section{- La autonomía de las cooperativas.}

Si bien, y a la usanza de sus pares soviéticos, ni la Constitución socialista, ni el Código Civil aluden a la autonomía cooperativa, la letra de la legislación especial de cooperativas siempre ha dado muestras formales de su existencia.

Este reconocimiento, por sus características analizadas supra, inscribía a las relaciones jurídicas entre el Estado y las cooperativas dentro de un modelo absorbente (Cracogna, 2001) o de dependencia (Rosemburg, 1985). Las normas resultantes del proceso de actualización del modelo socio-económico comienzan a producir contrastes y se comprueban avances en otras probables líneas de tendencia.

REVESCO No 117 - MONOGRÁFICO: Las sociedades cooperativas construyen un mundo mejor - ISSN: 1885-8031 - www.ucm.es/info/revesco 
Para una mejor comprensión de cuánto se ha avanzado en este sentido debe apuntarse de partida que el DL305/12 posee la tendencia a entender la naturaleza jurídica de la figura apegada a las sociedades mercantiles, lo que supera la concepción administrativo-patrimonial de las cooperativas agrarias. En este sentido podría explicarse que el tratamiento legal de la autonomía ha experimentado sensibles mejorías.

El otorgamiento de personalidad jurídica y la fijación del objeto social, aspectos medulares del proceso de constitución, aún mantienen un importante nivel de intervención por parte del Estado. En tal sentido nótese que se pasa por un modelo de registro con previa aprobación oficial de una autoridad pública, cuya obtención requiere de un proceso engorroso que involucra un número importante de instituciones de diversa naturaleza, con sus respectivas dependencias territoriales [Vid. artículos del 11 al 15 de la "Ley de Cooperativas de Producción Agropecuaria y de Créditos y Servicios", Ley 95 del 2 de noviembre de 2002; Capítulo II de los Reglamentos Generales para las CCS y CPA; Capítulo II, Sección Primera del RG/12 de las UBPC; el Capítulo II, Sección Tercera tanto del DL305/12 como del D309/12] y que la determinación del fin u objeto social de la empresa está sometido a la aprobación de la autoridad administrativa, quien fija la línea fundamental de producción [Vid. Artículo 19 a) de la "Ley de Cooperativas de Producción Agropecuaria y de Créditos y Servicios", Ley 95 del 2 de noviembre de 2002; artículo 8 y 9 de los Reglamentos Generales de las CPA y de las CCS respectivamente; artículo 4 del RG/12 de las UBPC y artículos 11 a) y 14 del D309/12]. Estas limitaciones a la autonomía cooperativa cuentan cada vez con menos sentido, en tanto existe consenso sobre la necesidad de liberar las fuerzas productivas.

En el desarrollo de las relaciones contractuales entre las empresas estatales y las cooperativas los cambios han sido más notables.

En el sector agrario, aun cuando la autonomía de la voluntad de las partes está limitada, en ocasiones, por los dictados de la autoridad administrativa superior, se han introducido cambios favorables que se proyectaron inicialmente en un "Plan de medidas inmediatas para resolver las ataduras que limitan el funcionamiento y la gestión de las UBPC" (Ministerio de la Agricultura cubano, 2012) que con posterioridad se concretó en el Reglamento General vigente y en otras disposiciones jurídicas.

Cuando se analiza el marco legal que rige el control y las relaciones contractuales de las Cooperativas no Agropecuarias cubanas, es fácil advertir como el legislador se separa del REVESCO No 117 - MONOGRÁFICO: Las sociedades cooperativas construyen un mundo mejor - ISSN: 1885-8031 - www.ucm.es/info/revesco 
tradicional modelo de dependencia que ha caracterizado a las cooperativas en el país, implementando fórmulas más avanzadas que equilibran de un lado libertad de gestión y control y del otro responsabilidad social (Vid. artículos 19, 20 y 25 del DL305/12).

Semejantes, por estrictos y engorrosos, resultan los procesos administrativos de aprobación y disolución de las cooperativas nacionales.

Para las agropecuarias, exige la ley se concluya en todo caso con Resolución autorizante del Ministerio de la Agricultura, en cuya obtención la voluntad de los cooperativistas es preterida o subyugada con respecto a otras más cercanas a la autoridad decisora. Entre las causales que dan lugar a la disolución se contemplan, además del acuerdo de sus respectivas Asambleas Generales, "el interés del Estado" y la "utilidad pública o el interés social". De estas últimas no se define el contenido en las normas reglamentarias, tornándose ambiguas e imprecisas, por lo que debería -al menos- preverse en la ley la posibilidad de recurrir judicialmente la resolución administrativa que dé lugar a la disolución con base en ellas.

Para las no agropecuarias, se dispone que no podrá extinguirse sin la previa aprobación del órgano, organismo o entidad nacional que autorizó su constitución, la que también puede revocar esta autorización ante el incumplimiento de los fines y principios que la motivaron. Estas facultades administrativas se manifiestan en el DL305/12 sin suficiente complemento reglamentario. A tono con ello, también es de exaltar que no se contemple en la ley la posibilidad de iniciar un proceso de disolución societario por libre acuerdo de la Asamblea General cuando, sin embargo, se ofrece autonomía estatutaria para prever causales de disolución.

Sobre esta base podríamos concluir que la implementación legal de la autonomía cooperativa en Cuba presenta síntomas de recuperación derivados del contexto de transformaciones en que se adentra el país; aunque parece restarle un largo trecho antes de poder exhibir los niveles necesarios y deseados.

- $\quad$ Los sectores de la economía susceptibles de desarrollo cooperativo.

Tal vez uno de los logros más importantes de la introducción de las cooperativas en el panorama cubano haya sido la diversificación de los sectores en los que es posible constituir este tipo de entidades.

REVESCO No 117 - MONOGRÁFICO: Las sociedades cooperativas construyen un mundo mejor - ISSN: 1885-8031 - www.ucm.es/info/revesco 
Según las informaciones que han trascendido estas están presentes en los sectores de gastronomía, construcción, trasporte, industria, alimentación, energía y servicios contables (Martínez \& Puig, 2014). En su mayoría se trata de actividades y estructuras que el Estado no ha gestionado de forma eficiente y de las que necesita irse desprendiendo para concentrarse en aquellas trascendentales para la economía (Sánchez, 2014).

A pesar del progreso experimentado y de la política de que el "incremento del sector no estatal de la economía, lejos de significar una supuesta privatización de la propiedad social, como afirman algunos teóricos, está llamado a convertirse en un factor facilitador para la construcción del socialismo en Cuba" (Partido Comunista De Cuba, 2011) se constata un desbalance importante entre las actividades que se desarrollan por cuenta propia y las que se han autorizado al sector cooperativo, toda vez que las primeras alcanzan las 181 actividades aprobadas. Este particular puede atribuirse al carácter reciente de las experiencias cooperativas no agropecuarios, pero es sin dudas un elemento a considerar, toda vez que en una sociedad socialista las formas de propiedad, producción, gestión, apropiación y distribución colectivas deben tener primacía sobre el resto.

\section{- $\quad$ Las instituciones de promoción y fomento del desarrollo cooperativo.}

Vinculada a la heterogeneidad de la legislación cooperativa se halla la diversidad de instituciones públicas que se relacionan con las cooperativas del país, creando un entramado de relaciones muy complejo, toda vez que cada tipología se supedita a la entidad estatal a la que correspondiera al ámbito específico de su actividad.

Ello explica la necesidad de un ente público que exista -únicamente- para diseñar e impulsar una política homogénea de atención y fomento del movimiento cooperativo nacional, con la cual se pondere la identidad universalmente reconocida de la figura por sobre la esfera de la economía en que se manifieste (Marín de León, 2011). Contar con un Instituto Cubano de Desarrollo Cooperativo (con dependencias territoriales bien apertrechadas y delimitación precisa de sus límites) facilitaría -por ejemplo- integrar el movimiento y coordinar sus relaciones con los entes a que deba vincularse. En suma, fortalecer el sector hasta que alcance niveles propicios para asumir -paulatinamente- su propia organización, regulación y control.

REVESCO No 117 - MONOGRÁFICO: Las sociedades cooperativas construyen un mundo mejor - ISSN: 1885-8031 - www.ucm.es/info/revesco 
- Las cooperativas de segundo o ulterior grado.

El DL305/12destinado a la regulación de las cooperativas no agropecuarias fija, entre los principios que han de sustentar el actuar de estas figuras, la "colaboración y cooperación entre cooperativas y con otras entidades" [artículo 4, inciso g)]. Además, el artículo 5, en su apartado primero admite la posibilidad de que se constituyan cooperativas de segundo grado. El tercer apartado del propio artículo copia -parcialmente- el concepto de cooperativas de segundo grado que ofrece el lineamiento 29 y que se pronuncia acerca de quiénes se asocian (dos o más cooperativas de primer grado) y cuáles son sus fines (organizar actividades complementarias afines o que agreguen valor a los productos y servicios de sus socios, o de realizar compras y ventas conjuntas, con vistas a lograr mayor eficiencia).

Ante la parca regulación de las cooperativas de cooperativas el mentado Decreto-Ley, en su Disposición Especial Cuarta, declara aplicable este cuerpo normativo a las cooperativas de segundo grado en aquellos términos en los que le sea pertinente. No obstante, el legislador en la Disposición Final Sexta insta al Consejo de Ministros a dictar el Reglamento de las Cooperativas de Segundo Grado en un plazo de 360 días luego de la publicación del DecretoLey en la Gaceta Oficial (11 de diciembre de 2012). Pero, bien entrado el año 2014, el Reglamento de las cooperativas no agropecuarias de segundo grado aún no se aprueba.

La dilación en el proceso de reglamentación, aprobación y constitución de las cooperativas de segundo grado puede encontrar fundamento en los problemas que han estado confrontando las cooperativas no agropecuarias de base. Es preciso que estas nuevas entidades consoliden sus indicadores socioeconómicos, que sus miembros ganen en experiencia teórico-práctica y que se genere una plataforma legal apropiada que organice un ambiente institucional coherente con la identidad del movimiento.

Sobre estos presupuestos, quizás sea prudente instrumentar los ensayos de este tipo en el sector agropecuario, donde existen antecedentes que los respaldan (Cruz, 2012) y donde el movimiento cooperativo nacional -con sus luces y sombras- está más consolidado. Lamentablemente en este sector de la economía aún no existe nada legislado al respecto.

- Las cooperativas y la inversión extranjera.

El legislador cubano ha optado por el mantenimiento en la recién aprobada Ley No. 118, "Ley de la Inversión Extranjera" de 16 de abril de 2014 de las modalidades REVESCO No 117 - MONOGRÁFICO: Las sociedades cooperativas construyen un mundo mejor - ISSN: 1885-8031 - www.ucm.es/info/revesco 
anteriormente aceptadas (empresa mixta, empresa de capital totalmente extranjero y contrato de asociación económica internacional. Vid. Sección I, Capítulo V).

La participación de las cooperativas dentro de las actividades de la inversión extranjera vendría dada en calidad de inversionistas nacionales, toda vez que cuentan con personalidad jurídica, dentro de un proyecto con capital extranjero. Esta novedad supondría un notable avance respecto a la situación precedente y crea la oportunidad para potenciar su implicación con el movimiento cooperativo mundial y especialmente regional, aprovechando el marco jurídico que le ofrece la Alianza Bolivariana para las Américas (ALBA) y el resto de mecanismos integracionistas de los que Cuba forma parte.

- Las cooperativas y el empleo.

Cuando las proyecciones de la economía para el periodo 2011-2015 se referían a la reducción de más de 500000 trabajadores en el sector estatal, donde el exceso de plazas sobrepasa el millón (Central de Trabajadores de Cuba, 2010), surgió el imperativo de “asegurárseles la posibilidad de obtención -por medios legales- de los recursos necesarios para su existencia y la de su familia, así como de su desarrollo espiritual y cultural" (Rodríguez, 2011:69). En esta situación se hizo evidente que la nación necesitaba generar empleos y nuevas capacidades para su desarrollo reivindicando la relevancia delos sectores no estatales, dentro delos que se encuentra el cooperativo.

La creación de cooperativas, al amparo de la legislación experimental, se presenta como un medio para asegurar empleo y sustento de quienes devengan en socios. En el caso de los trabajadores de las entidades del sector estatal que se transforman en cooperativas, en particular, se les ha concedido prioridad para convertirse en socios [artículo 10.2 c) en relación con el artículo 6 delDL305/12] con lo que estos tendrían solamente que cambiar su condición dentro de la empresa.

El recién promulgado Código de Trabajo, Ley No. 116 de 17 de junio de 2014, reconoce que las cooperativas pueden figurar, además, como entidades empleadoras. A los trabajadores contratados por estas se le reconocen los deberes y derechos establecidos en la legislación general o en la específica para la actividad de que se trate (artículo 78). Esta regulación abre un primer paso en la unificación del sistema laboral del país, al incluir la norma general a las relaciones laborales de los distintos sectores presentes en el país.

REVESCO No 117 - MONOGRÁFICO: Las sociedades cooperativas construyen un mundo mejor - ISSN: 1885-8031 - www.ucm.es/info/revesco 
En cuanto a las repercusiones en la esfera laboral de la cooperativa, la ampliación legal de las posibilidades de desarrollo cooperativo crea un escenario propicio para una mayor inclusión y empoderamiento de las mujeres. La superación de la limitación del cooperativismo solo en el sector agropecuario, donde las concepciones tradicionales de los roles se muestran más resistentes, permite que se exploten al máximo sus potencialidades. En este sentido es relevante, además, el hecho de que el potencial, en cuanto a calificación profesional femenino en los sectores económicos no agrarios es significativo en Cuba.

\section{- Las cooperativas y el desarrollo local.}

El proceso de perfeccionamiento del modelo socioeconómico ha apostado por un fortalecimiento recíproco del sector cooperativo y del desarrollo local, toda vez que la legislación que ordenaba estas relaciones con anterioridad, dadas sus impresiones, no alcanzó su finalidad a cabalidad (Fernández, 2006).

Con el Decreto-Ley No. 300, sobre la entrega de tierra en usufructo, de 17 de enero de 2014, se procura influir favorablemente en el desarrollo del entorno en que se enclavan las cooperativas, procurando que las ya existentes formas agropecuarias aseguren su explotación "racional y sostenible atendiendo a la aptitud de los suelos, en función de la producción agropecuaria, forestal y de frutales" (art. 1, apartado 1 del DL300/12).

Como parte de esta línea de trabajo se han desarrollado, además, las micro y minindustrias. Siendo así que "la perspectiva de desarrollo de las cooperativas en Cuba, incluye la utilización con eficiencia de las capacidades de producción de las minindustrias del sector de cooperativas agrícolas. De tal manera que permita incrementar las producciones locales de alimentos" (Fragoso, 2011:9).

En el sector de las construcciones, que es clave para solucionar las necesidades generales de la producción y de la población en materia de viviendas ha sido considerado, también, como un espacio propicio para el desarrollo de formas cooperativas (Resumen de las intervenciones en el Sexto Período Ordinario de las Sesiones de la Séptima Legislatura de la Asamblea Nacional del Poder Popular, 2010).

A pesar de estas positivas proyecciones, el sector del turismo se mantiene ajeno a la introducción de las cooperativas, aun cuando como resultado del Lineamiento 264 -que orienta "Diseñar y desarrollar como parte de la iniciativa municipal por los territorios, ofertas REVESCO No 117 - MONOGRÁFICO: Las sociedades cooperativas construyen un mundo mejor - ISSN: 1885-8031 - www.ucm.es/info/revesco 
turísticas atractivas como fuente de ingreso en divisas (alojamiento, servicios gastronómicos, actividades socioculturales e históricas, ecuestres, de campiñas, turismo rural, observación de la flora y la fauna, entre otras)"- esto sería viable.

Una de las transformaciones más sustanciales en el marco de estas relaciones está asociada a la materia fiscal. La Ley No. 113 "Del Sistema Tributario", de 21 de noviembre de 2012, incluye en su artículo 310 la posibilidad para los municipios de acceder a financiamiento a partir de que "los sujetos de la Contribución Territorial que realicen sus operaciones en pesos cubanos (CUP) y pesos convertibles (CUC), pagan en ambas monedas de forma proporcional a sus ingresos".

Esta norma obedece a lo dispuesto en los Lineamientos del 56 al 65, donde consta la aspiración de crear un vínculo financiero directo entre el desarrollo del municipio y el aporte que el mismo sea capaz de hacer con sus producciones y servicios. Uno de los sujetos principales de dicha contribución lo son las cooperativas, con lo que se liga su suerte a la del desarrollo de su localidad.

- Las cooperativas y la educación cooperativa.

La educación cooperativa, en tanto principio cooperativo, cuenta con importantes antecedentes en Cuba. Algunos incluso estudiados desde la ciencia de la Educación (Alfonso).

No obstante, el escenario se dinamiza y complejiza con la aprobación de los Lineamientos y la promulgación de la legislación experimental sobre las cooperativas no agropecuarias. La novedad del tema y el debate al respecto ha creado avidez en la población en sentido general, entre los recién devenidos socios y entre los profesionales que han debido y deben acompañar el proceso de creación y desarrollo de las nuevas cooperativas. Ello supone el reto de diversificar las formas, contenidos y escenarios en los que se desarrolla la enseñanza en torno al tema cooperativo.

Particular interés reviste en este sentido la introducción de la materia del Derecho de Cooperativas dentro del Plan de Estudios D en la Carrera de Licenciatura en Derecho en Cuba, como parte del currículo optativo de la misma. Esto responde a la necesidad de flexibilizar los planes de estudio a fin de que sea posible la introducción de materias que sean de interés científico y social pero que no se encuentran previstas dentro del currículo base, con lo que se permite dar respuesta a particulares demandas de los diversos REVESCO No 117 - MONOGRÁFICO: Las sociedades cooperativas construyen un mundo mejor - ISSN: 1885-8031 - www.ucm.es/info/revesco 
contextos espaciales y temporales. En ese espacio curricular optativo ha encontrado cabida el Derecho de Cooperativas, dado que es una demanda social impostergable la preparación de los juristas para asesorar el universo de potenciales cooperativistas en el país.

De lo antes expuesto se colige que la influencia de la regulación legal de la cooperativa dentro de la sociedad cubana ha tenido efectos que se transversalizan a diversos planos de la misma. Conscientes de ello se impone, para un mejor desarrollo de esta figura, que se continúe optimizando y que se potencien aquellos elementos que aún pueden ser objeto de perfeccionamiento. Solo así se puede ser consecuentes con la aspiración de construir un mundo mejor, mediante el perfeccionamiento del sistema social socialista a través del “desarrollo económico del país y la elevación del nivel de vida de la población, conjugados con la necesaria formación de valores éticos y políticos de nuestros ciudadanos" (VI Congreso del Partido Comunista de Cuba, 2012).

\section{CONCLUSIONES}

A partir de lo anterior, podemos concluir que:

1. En los ordenamientos jurídicos socialistas la naturaleza de la cooperativa se ha reducidoa sucomponente patrimonial, además de haber tenido un papel subsidiario y dependiente con respecto al Estado en su constitución y funcionamiento, todo lo cual la ha limitado en el desplieguede su potencial productivo y socializador. Por tanto, en el socialismo también requiere ser concebida jurídicamente en armonía con sus rasgos y principios típicos.

2. Las limitaciones de la regulación jurídicas de la cooperativa en Cuba durante la etapa socialista se han manifestado, entre otros aspectos, en la concepción reduccionista de su naturaleza, en el no reconocimiento general a los trabajadores del derecho a asociarse en cooperativas, en la relegación de la figura al sector agropecuario de la economía, en la estrechaprevisión legal de los efectos a los que se concibe, y en el establecimiento de un régimen paternalista para su funcionamiento. Todo lo cualha lastimado las potencialidades trasformadoras de la institución.

3. En el ordenamiento jurídico socialista cubano aún persisten importantes limitaciones para la cooperativa; sin embargo, con el recién iniciado proceso de actualización del sistema socioeconómico nacional, se avanza en este sentido y se abren nuevas perspectivaspara

REVESCO No 117 - MONOGRÁFICO: Las sociedades cooperativas construyen un mundo mejor - ISSN: 1885-8031 - www.ucm.es/info/revesco 
ponderar el papel de las cooperativas en el desarrollo económico y consolidación de las conquistas sociales del país.

\section{BIBLIOGRAFÍA}

Textos

ALFONSO, P. (s.f.) La educación cooperativa: regla de oro del cooperativismo. Pinar del Río: Disponible en

http://ftp.ceces.upr.edu.cu/centro/repositorio/Textuales/Libros/La_Educacion_cooperativa _regla_de_oro_del_cooperativismo/. Recuperado el 12 de septiembre de 2014.

ÁlVAREZ, F. (1989) Comentarios a la Constitución socialista cubana. La Habana: Ed. Pueblo y Educación. 434 p.

AZCUY, H.M. (2000) Análisis de la Constitución cubana. Revista Papeles de la FIM, No. 14, 2da. Época, Madrid, pp. 7-144.

CARRANZA, J.; GUTIÉRREZ, L. \& MOREAL, P. (2004) Cuba: la reestructuración de la economía. Una propuesta para el debate. En: PÉREZ, L. \& PRIETO, M. Temas de Derecho Constitucional cubano. La Habana:Ed. Félix Varela. pp. 65-74. ISBN: 959-258739-6.

CASUllerA, R. (1986) La Propiedad Personal en nuestra Constitución. Revista Jurídica, No. 10, enero - marzo, La Habana, pp. 50 -68.

CRACOGNA, D. (2001) La legislación cooperativa en el mundo de hoy. Presentado en el Seminario de Legislación Cooperativa, 22 de noviembre, Uruguay: Disponible en http://www.neticoop.org.uy/article118.html Recuperado el 7 de noviembre de 2010.

CRUZ, J. (2012) Cooperativas de segundo grado en Cuba (experiencia de 1982 a 1986). Ponencia presentada en el VIII Congreso Internacional de Derecho Agrario, La Habana, 24,25 y 26 de abril.

FERNÁNDEZ, L.A. (2006) Lecturas en pro del cooperativismo, ante las imprescindibles transformaciones económicas del socialismo cubano. Cienfuegos: Ed. Universo Sur.160 p. ISBN: 978-959-257-172-3.

FERNÁNDEZ, L.A. (2012) La Cooperativa. Bases para su Legislación en Cuba. La Habana:

Ed. Ciencias Sociales. 315 p. ISBN: 978-959-06-1400-2.

FRAGOSO, O. (2011) Desarrollo y Perspectivas de las Minindustrias en las Cooperativas Agrícolas en Cuba. En:Informe final del Seminario-Taller sobre experiencias de 
desarrollo de cooperativas agrícolas y minindustrias agroalimentarias en América Latina y el Caribe. La Habana: Disponible en http://www.iadb.org/intal/intalcdi/PE/2011/08213a02.pdf. Recuperado el 25 de mayo de 2013.

FERRERO, D. (2006) La crisis del socialismo real. Semejanzas y diferencias entre las disidencias del bloque del este. Historia Actual Online, No. 11. Disponible en http://dialnet.unirioja.es/servlet/fichero_articulo?codigo=2380205 Recuperado el 12 de mayo de 2012.

IOFFE, O.S. (1960) Derecho Civil Soviético. México D.F: Instituto de Derecho Comparado, Universidad Nacional Autónoma de México, Imprenta Universitaria. Disponible en http://www.bibliojuridica.org/libros/libro.htm?l=611 Recuperado el 11 de febrero de 2009.

JÁLFINA, R. (1981) El Derecho de propiedad del Estado en la URSS. Moscú:Ed. Progreso.

JIMÉNEZ, R. (2005) Aspectos fundamentales del desarrollo cooperativo cubano. Disponible en www.flacso.uh.cu/sitio_revista/num3/articulos/art_RJimenez2.pdf Recuperado en junio de 2013.

KAPLAN DE DRIMER, A. \& DRIMER, B. (1981) Las cooperativas. Fundamentos Historia - Doctrina. 3ra. Edición. Buenos Aires: Ed. Intercoop. 630 p.

LASO, J. (1977). La función del Derecho en el cambio social. En Revista Argumentos (7), pp. $15-17$.

LOWRY, M. (2003). Los valores posibles de una nueva civilización . En G. MINÀ, Un mundo mejor es posible. La Habana: Ediciones UNIÓN.

MARÍN DE LEÓN, I. (2011) Perfeccionamiento de las relaciones Estado - cooperativas Cuba en los marcos de la actualización del modelo económico. Tesis en opción al Título Académico de Master en Administración de Empresas Agropecuarias. Pinar del Río: Univerisdad de Pinar del Río.

MARTÍNEZ, L. \& PUIG, Y. (2014) Insta Raúl al análisis crítico sobre la marcha de la implementación. Periódico Trabajadores, 3 de marzo, La Habana, p. 4.

PETR, D. (2004) El Derecho de Propiedad en los Códigos Civiles Socialistas de Checoslovaquia. En: Anuario de la Facultad de Derecho, vol. XXII. Praga: Charles University, p. 465-472. ISSN: 0213-988-X. Disponible en http://dialnet.unirioja.es/servlet/fichero_articulo?codigo=1104235 Recuperado el 12 mayo de 2012.

REVESCO No 117 - MONOGRÁFICO: Las sociedades cooperativas construyen un mundo mejor - ISSN: 1885-8031 - www.ucm.es/info/revesco 
PIÑEIRO, C. (2011) Prólogo. En: PIÑEIRO, C. Cooperativas y Socialismo. Una mirada desde Cuba. La Habana: Ed. Caminos, p. 7-30. ISBN 978-959-303-033-5.

RODRÍGUEZ, C. (s.f.) Panorama histórico de la función de la cooperación en el desarrollo económico de los países colectivistas. Disponible en http://dialnet.unirioja.es/servlet/fichero_articulo?codigo=1340686, Recuperado el 12 de mayo de 2012.

RODRÍGUEZ, O. (2011) La cooperativa como figura jurídica. Perspectivas constitucionales en Cuba para su aprovechamiento en otros sectores de la economía nacional diferentes al agropecuario. Madrid: Dikinson S.L. 98 p.

ROSEMBURG, T. (1985) La Empresa Cooperativa. Barcelona: CEAC.

SÁNCHEZ, A. (s.f.) El sector agrario en Bulgaria y Rumanía a la luz de las reformas actuales. Disponible en:

http://www.magrama.gob.es/ministerio/pags/biblioteca/revistas/pdf_ays\%2Fa063_05.pdf Recuperado el 12 de mayo de 2012.

SÁNCHEZ, O. (2014) La materialización de una estrategia, Periódico Granma (Suplemento Especial), 10 de enero, La Habana, pp. 2 - 4.

VEGA, J. (1988) Derecho Constitucional revolucionario en Cuba. La Habana: Ed. Ciencias Sociales. 310 p.

YERA, L.M. (2007) La ley olvidada de la transición y el proyecto económico socialista en el siglo XXI. Revista Temas, No. 50-51, abril - septiembre, La Habana, pp. 109 - 125.

\section{Documentos}

MINISTERIO DE LA AGRICULTURA. (2012). Compendio de Documentos sobre las $U B P C$. La Habana.

PARTIDO COMUNISTA DE CUBA (2011). Informe Central al VI Congreso del Partido Comunista de Cuba. Disponible en: http://www.cubadebate.cu/opinion/2011/04/16/textointegro-del-informe-central-al-vi-congreso-del-pcc/Recuperado el 26 de enero de 2013.

Pronunciamiento de la Central de Trabajadores de Cuba (13 de septiembre 2010).

Disponible en: www.cubadebate.cu/noticias/2010/09/13/reducira-cuba-medio-millon-deplazas-en-elsector-estatalRecuperado el 6 de octubre de 2010.

Resumen de las intervenciones en el Sexto Período Ordinario de las Sesiones de la Séptima legislatura de la Asamblea Nacional del Poder Popular (17 de diciembre de 2010) Análisis de los Lineamientos de la Política Económica y Social del Partido y la 
Revolución (Segunda Jornada), (Versiones Taquigráficas - Consejo de Estado). Disponible en: http://www.juventudrebelde.cu/cuba/2010-12-18/resumen-de-lasintervenciones-en-el-sexto-periodo-ordinario-de-sesiones-de-la-septima-legislatura-de-laasamblea-nacional-18-de-diciembre/Recuperado el 18 de diciembre de 2013.

Transformaciones en sector estatal exigen más agilidad, Disponible en: http://www.cubadebate.cu/noticias/2012/04/28/transformaciones-en-sector-estatal-exigenmas-agilidad/ Recuperado el 20 de mayo de 2013.

VI CONGRESO DEL PARTIDO COMUNISTA DE CUBA (2012) Lineamientos de la Política Económica y Social del Partido y la Revolución. La Habana.

\section{Legislación}

Constitución de la República de Cuba de 24 de febrero de 1976 (actualizada) (2004) Ministerio de Justicia, La Habana.

Código Civil. Ley No. 59 de 16 de julio de 1987 (actualizado) (1998) Ministerio de Justicia, La Habana.

Ley No. 95. Ley de Cooperativas de Producción Agropecuaria y de Créditos y Servicios. Gaceta Oficil Ordinaria de 29 de noviembre de 2002.

Ley No. 113. Del Sistema Tributario. Gaceta Oficial No. 053 de 21 de noviembre de 2012.

Ley No. 118. Ley de la Inversión Extranjera. Gaceta Oficial No. 20 Extraordinariade 16 de abril de 2014.

Ley No. 116. Código de Trabajo. Gaceta Oficial No. 29 Extraordinaria de 17 de junio de 2014.

Decreto-Ley No. 142 aprobado el 20 de septiembre de 1993. Sobre las Unidades Básicas de Producción Cooperativa. Disponible enMINISTERIO DE LA AGRICULTURA (2012). Compendio de Documentos sobre las UBPC. La Habana.

Decreto-Ley No. 300. Sobre la entrega de tierra en usufructo. Gaceta Oficial No. 4 Extraordinaria de 17 de enero de 2014.

Decreto-Ley No. 305. De las Cooperativas No Agropecuarias. Gaceta Oficial No. 53 Extraordinaria de 11 de diciembre de 2012.

Acuerdo No. 5454 del Comité Ejecutivo del Consejo de Ministros, contentivo del Reglamento General de las Cooperativas de Produccion Agropecuaria (ANEXO 1) y del Reglamento General de las Cooperativas de Creditos y Servicios (ANEXO 2). Gaceta Oficial No. 20 de 4 de julio de 2005 .

REVESCO No 117 - MONOGRÁFICO: Las sociedades cooperativas construyen un mundo mejor - ISSN: 1885-8031 - www.ucm.es/info/revesco 
Decreto No. 309. Reglamento de las Cooperativas No Agropecuarias. Gaceta Oficial No. 53 Extraordinaria de 11 de diciembre de 2012.

Resolución No. 574 de 13 de agosto de 2012 del Ministerio de la Agricultura. Reglamento General de las Unidades Básicas de Producción Cooperativa. Disponible enMINISTERIO DE LA AGRICULTURA (2012). Compendio de Documentos sobre las UBPC. La Habana.

REVESCO No 117 - MONOGRÁFICO: Las sociedades cooperativas construyen un mundo mejor - ISSN: 1885-8031 - www.ucm.es/info/revesco 